\title{
As múltiplas dimensões do poético
}

Eduardo Veras $^{I}$

$\mathbf{N}$

O NOvO livro de Fernando Paixão, Acontecimento da poesia, o velho e desgastado debate entre formalistas e realistas, entre os adeptos da autonomia estética da poesia e os defensores da necessária abertura do poema para a vida, para o mundo extralinguístico, é superado de maneira elegante e inteligente. Paixão não reúne ali apenas textos sobre textos, análises centradas no isolamento do texto literário, embora a atenção formal não deixe de estar presente em suas análises. Depreende-se pela leitura da coletânea que a tarefa do crítico é mais ampla e transdisciplinar, pois se coloca em razão de um "entendimento global e orgânico do ato poético" (p.42), conforme se lê no excelente artigo dedicado a Alfredo Bosi, cuja influência sobre a formação de Paixão é nítida e assumida. Referindo-se à descoberta de $O$ ser e o tempo da poesia (Bosi, 1977), Paixão escreve: "O impacto da leitura foi imediato, pois o autor de História concisa da literatura brasileira (1970) engendra nesse trabalho uma visão holística da poesia, envolvendo intrincadamente os aspectos formais, temáticos e históricos" (p.42).

Como na obra de Bosi, a poesia é pensada aqui como uma "intervenção", isto é, como algo que, sem se negar como forma, irrompe como acontecimento no curso do tempo, da história, do destino dos homens. Exemplo privilegiado disso se encontra no texto de abertura, "Poesia ao front: Israel e Palestina", cujo mote é a decisão da Autoridade Nacional Palestina, no início dos anos 2000, de "introduzir literatura israelense em seus currículos” em resposta a uma decisão anterior, do ministro da Educação de Israel de incluir a obra de Mohamoud Darwish nas aulas de literatura do país (p.15). Naquele momento, a poesia é um acontecimento, uma irrupção civilizatória no âmbito de um conflito secular, e, para além da diplomacia, é uma oportunidade para ambos os povos "retornar[em] ao mistério primeiro da língua” (p.15), àquilo que os une, além (ou aquém) dos conflitos recentes, como povo de origem comum e, mais ainda, como seres dotados de linguagem. É nesse sentido que Paixão observa que

[...] escapa aos senhores dos exércitos
o que diz a poesia. Metáforas, ritmos
e versos - motivados pelo desvio pró-
prio da imaginação - transformam-se
num mundo próprio de afinidades,
em nome de outra lógica, que parece
abrir mão da autoridade. (p.17)

Essa “outra lógica” é, antes de tudo, uma "outra voz", nos termos de Octavio Paz (1993, p,40), para quem a poesia se inscreve no tempo "entre a revolução e a religião", sua voz sendo "outra porque é a voz das paixões e das visões; é de outro mundo e é deste mundo, é antiga e é de hoje mesmo, antiguidade sem datas".

É, portanto, o caráter ambivalente do ato poético, acontecimento histórico e linguístico, social e estético, revolucionário e religioso, que orienta a visão de poesia que subjaz os textos de Paixão. Ao fenômeno da irrupção histórica de um discurso outro, desviante, acrescentemos o impacto do acontecimento poético no seio da própria tradição literária, história outra, cuja continuidade se dei- 
xa afetar e engendra ao mesmo tempo a história do mundo. $\mathrm{O}$ crítico se dedica a pensar o em torno do poeta, espaço social, geopolítico, mas também literário. Destacam-se, nesse âmbito, o excelente ensaio sobre os impactos de Macunaima na poesia modernista, reflexão que se prolonga para muito além da geração de 1922, e os dois ensaios centrados no diálogo-confronto entre as tradições poéticas do Brasil e de Portugal.

As "conexões poéticas luso-brasileiras", para retomar o título de um dos ensaios referidos acima, interessam duplamente ao crítico, em razão do exercício de comparação entre tradições aparentadas, mas, claro, em razão também de um fato biográfico, sua origem luso-brasileira, conforme ele próprio afirma no outro ensaio em questão, intitulado "Modernismos em confronto: Brasil e Portugal":

É na condição de Português de nascimento, transferido para o Brasil desde muito cedo (aos seis anos de idade) e interessado nessa ponte que une o colorido dos trópicos à tradicional melancolia portuguesa, que sempre me atraiu uma visão comparativa entre as ideias que movimentaram o modernismo literário brasileiro, tal como veio a ocorrer na Semana de Arte Moderna de 1922, em contraposição à eclosão do grupo da revista Orphen de Portugal. (p.63)

Transitando entre as duas tradições, Paixão não se nega a reconhecer a indelével marca subjetiva de toda visada crítica. Aqui, penso que o retorno a $\mathrm{Al}$ fredo Bosi pode iluminar mais uma vez a questão. Em “A interpretação da obra literária”, o crítico e professor emérito da Universidade de São Paulo nos ensina que
[...] o intérprete é, por excelência, um mediador.. Ele trabalha rente ao texto, mas com os olhos postos em um processo formativo relativamente distante da letra.

Interpres chamavam os romanos àquele que servia de agente intermediário entre as partes em litígio. Com o tempo, interpres assumiu também a função de tradutor: o que transporta o significado da sua forma original para outra; de um código primeiro para um código segundo; o que pretende dizer a mesma mensagem, mas de modo diferente. A interpretação opera nessa consciência intervalar, e ambiciona traduzir fielmente o mesmo, servindo-se dialeticamente do outro. O outro é o discurso do próprio hermeneuta. (Bosi, 2003, p.465)

A exemplo do que escreve Bosi, o trabalho crítico do interpres Fernando Paixão se realiza no intervalo entre várias linhas de força: o texto, pensado como matéria linguística; o contexto, tempo no qual irrompe e intervém o poema; a subjetividade crítica (p.43), o discurso outro do hermeneuta, carregado de história e geografia, localizado num tempo e num espaço, e portador de uma sensibilidade, uma formação e uma cosmovisão.

Essa multiplicidade de perspectivas se materializa na própria estrutura do livro, dividido em três partes: "Da poesia", "Dos poetas" e "Do autor". Essa estrutura tripartida, que pode ainda apresentar outras subdivisões internas, nos permite dizer que a abordagem de Paixão busca se apropriar do fenômeno poético a partir de um constante movimento de aproximação e distanciamento do poema. Isso explica a preocupação do crítico não apenas com o texto, mas com os ar- 
redores do texto (pensemos no já citado ensaio sobre a questão Israel-Palestina), do poeta (pensemos no ensaio "Ao redor de José Paulo Paes" e vários outros nos quais o poeta analisado é confrontado com seu ambiente pessoal, histórico e literário) e, no final das contas, do próprio crítico, cuja voz, como se viu acima, é entendida como voz humana, dotada de subjetividade e temporalidade.

Mas não deixemos de ressaltar que essa voz humana, subjetiva, que carrega consigo um mundo de referências e emoções prévias também assume uma tarefa de cunho coletivo, pois é o crítico aquele que mais contribui para a sobrevivência das obras e para o alargamento dos debates em torno delas. Nesse sentido, Paixão não se conforma em revisitar escritores e obras consagradas entre nós, o que faz muito bem, diga-se de passagem, como José Paulo Paes, Fernando Pessoa, Mário de Andrade, Vinicius de Moraes, mas também busca introduzir na conversa nomes que circulam menos entre nós, leitores brasileiros do século XXI, como o do poeta franco-chinês François Cheng, recém-traduzido (por Bruno Palma) e publicado no Brasil (Duplo canto e outros poemas. Cotia: Ateliê, 2011) e do poeta croata Radovan Ivsic.

A apresentação desses poetas ao público brasileiro, o primeiro em tradução para a nossa língua e o segundo a partir de traduções esboçadas por Paixão a partir da edição francesa, se dá justamente como um convite à ampliação da conversa, como proposta de ampliação de nossos horizontes literários. Assumindo uma das mais nobres e urgentes tarefas da crítica, Paixão nos apresenta o outro convidando-nos ao mesmo tempo a pensar em nós mesmos, num jogo que reproduz o movimento que venho descrevendo nesta resenha, o movimento de negociação entre os mundos do texto e do leitor. No caso de Cheng, cuja situação intercultural, formado e vivendo na fronteira entre Oriente e Ocidente, por si só já aponta para a multiplicidade e o trânsito de linhas de força envolvidas no processo de recepção de um poeta, somos levados a recuperar, no âmbito de nossas próprias referências literárias, exemplos que nos forneçam um primeiro parâmetro de leitura para a compreensão de sua poética centrada nas coisas, no mundo objetivo, nos elementos da natureza - como não evocar João Cabral de Melo Neto, por exemplo? Ou em outra possível chave de leitura, Manoel de Barros? Seja como for, Paixão nos mostra como a apresentação de um "novo" poeta é também um acontecimento no mundo da poesia, acontecimento que mobiliza poeta, tradutor, crítico e leitor: "Que a poesia de Cheng aconteça, sob os olhos do leitor, pura como a água (p.112; grifo meu).

A todas essas vozes e perspectivas, acrescentemos, para encerrar, uma última: a voz do poeta Fernando Paixão, que se insinua entre as frases do crítico ao longo de toda a coletânea e se revela de vez nas duas entrevistas que constam da parte final do livro. Afirmando a irredutibilidade do poético ao intelecto, relegado pelo poeta à “segunda dimensão [da] matéria original” (p.144), Paixão faz o elogio da emoção como centro irradiador de sua poética. Como o crítico, o poeta também fala em "ato poético", acontecimento que une homens e anjos decaídos no mesmo "círculo da imperfeição" (p.146), no enfrentamento moderno do caos, da violência, da distopia. Penso que o livro de Paixão como um 
todo busca iluminar justamente a eternidade fugaz dessa irrupção que se inscreve no tempo para superá-lo e curá-lo momentaneamente, eternidade "comprimida no instante vertical de alguns poemas", utopia poética desde sempre e para sempre perseguida pelo poeta, mas também pelo crítico e por todo leitor de poesia.

Referências

BOSI, A. História concisa da literatura brasileira. São Paulo: Cultrix, 1970.

- O ser e o tempo da poesia. São Paulo: Cultrix; Edusp, 1977. . A interpretação da obra literária. In: __. Céu, inferno. São Paulo: Duas Cidades; Editora 34, 2003.

PAIXÃO, F. Acontecimento da poesia. São Paulo: Illuminuras, 2019.

PAZ, O. A outra voz. Trad. Wladir Dupont. São Paulo: Siciliano, 1993.

Eduardo Veras é professor adjunto do Departamento de Estudos Literários da Universidade Federal do Triângulo Mineiro (UFTM). É pesquisador, crítico, poeta e tradutor. @- eduardohnveras@gmail.com https://orcid.org/0000-0003-4803-1482

I Instituto de Educação, Letras, Artes, Ciências Humanas e Sociais, Universidade Federal do Triângulo Mineiro, Uberaba, Minas Gerais, Brasil.

Recebido em 28.6.2019 e aceito em 30.7.2019. 